\title{
Unusual Etiology of Chronic Posterior Leg Pain in a Running Athlete: Could It Be a Schwannoma? A Case Report and Review of the Literature
}

\author{
Naoufal Elghoul $\mathbb{D}^{1},{ }^{1}$ Omar Zaddoug, ${ }^{1}$ Mohammed Tbouda, ${ }^{2}$ Mohammed Benchakroun, ${ }^{1}$ \\ and Abdeloihab Jaafar ${ }^{1}$ \\ ${ }^{1}$ Department of Orthopedic Surgery and Traumatology, Military Hospital Mohammed V (HMIMV), Faculty of Medicine \\ and Pharmacy, Mohammed V University of Rabat, BP 10100, Morocco \\ ${ }^{2}$ Department of Anatomy Pathology, Military Hospital Mohammed V (HMIMV), Faculty of Medicine and Pharmacy, Mohammed V \\ University of Rabat, BP 10100, Morocco
}

Correspondence should be addressed to Naoufal Elghoul; naoufal.elghoul@gmail.com

Received 24 March 2019; Revised 12 October 2019; Accepted 28 October 2019; Published 12 November 2019

Academic Editor: Georg Singer

Copyright (C) 2019 Naoufal Elghoul et al. This is an open access article distributed under the Creative Commons Attribution License, which permits unrestricted use, distribution, and reproduction in any medium, provided the original work is properly cited.

\begin{abstract}
Schwannomas represent only $5 \%$ of all soft tissue tumors. As a variant of this tumor, the plexiform schwannoma is rare accounting for less than 5\% of all schwannomas. Herein, we report a rare case of a 49 -year-old athlete who suffered from a pain in the posterior aspect of the right leg one year before his presentation. Initially, a radiograph of his right leg showed no abnormality, and so, the emergency physician discharged him on analgesics and anti-inflammatory medications, and rest was advised. The persistent pain obliged the patient to consult our orthopedic department. On examination, we found a firm mass in the proximal medial aspect of his right leg. The neurovascular exam was normal. Sonography of the leg was not conclusive. Therefore, magnetic resonance imaging was performed, and a hemangioma or schwannoma was suspected. The patient underwent surgery in which the entire tumor mass was shelled out in one piece with no damage. The histopathological finding was concomitant with a plexiform schwannoma. Follow-up evaluation, sixteen months later, showed no evidence of recurrence, and the patient has regained his previous level of sportive activities. So, given the case described here, despite the rarity of the schwannoma, it should be taken into consideration as a possible diagnosis in such situation to promote early diagnosis and appropriate treatment.
\end{abstract}

\section{Introduction}

Schwannomas, also known as neurilemomas, are benign peripheral nerve sheath tumors composed exclusively of Schwann cells; they account for only $5 \%$ of all soft tissue tumors $[1,2]$. These lesions are commonly encountered in the head and neck region [3]. In the lower limb, they occur rarely in collateral branches of a nerve [4-7]. Furthermore, as a variant of this tumor, the plexiform schwannoma is rare which accounts for less than $5 \%$ of all schwannomas and it is difficult to diagnose [8]. Moreover, it is often misdiagnosed due to lack of awareness and often confused with other common lesions like lipoma and fibroma of the ganglion [9]. However, its diagnosis can be suspected on sonography, computed tomography, and magnetic resonance imaging examination, and it is confirmed by pathological analysis of the operative specimen $[10,11]$. To the best of our knowledge, the case presented here is among the extremely rare cases of posterior leg pain in running athletes due to an atypical localization of a rare schwannoma.

\section{Case Presentation}

A 49-year-old athlete suffered from pain localized in the posterior aspect of the right leg since one year, with no reported history of trauma or prick injury. He consulted initially an emergency physician who has requested a radiograph of the right leg which showed no pathology, and so, the patient was discharged on analgesics and anti-inflammatory medications, and rest was advised. 


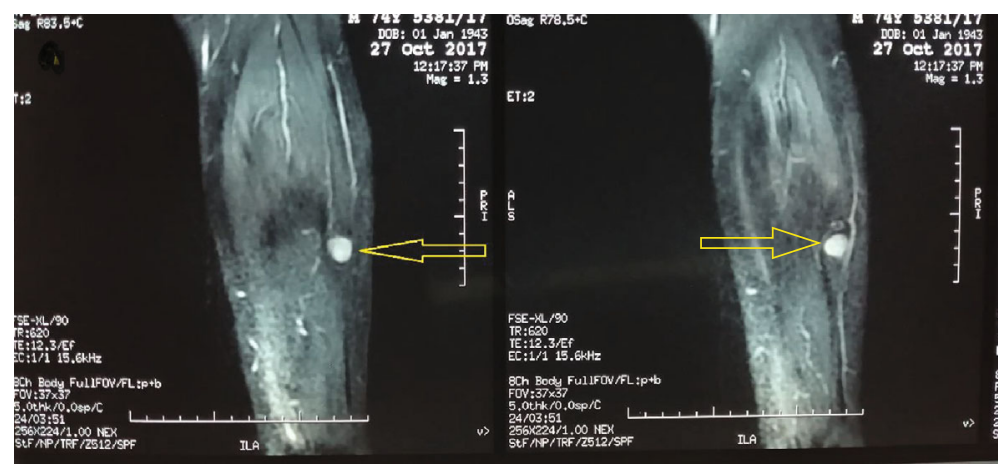

FIGURE 1: MRI T1 fat suppression showed the tumor mass (arrows).

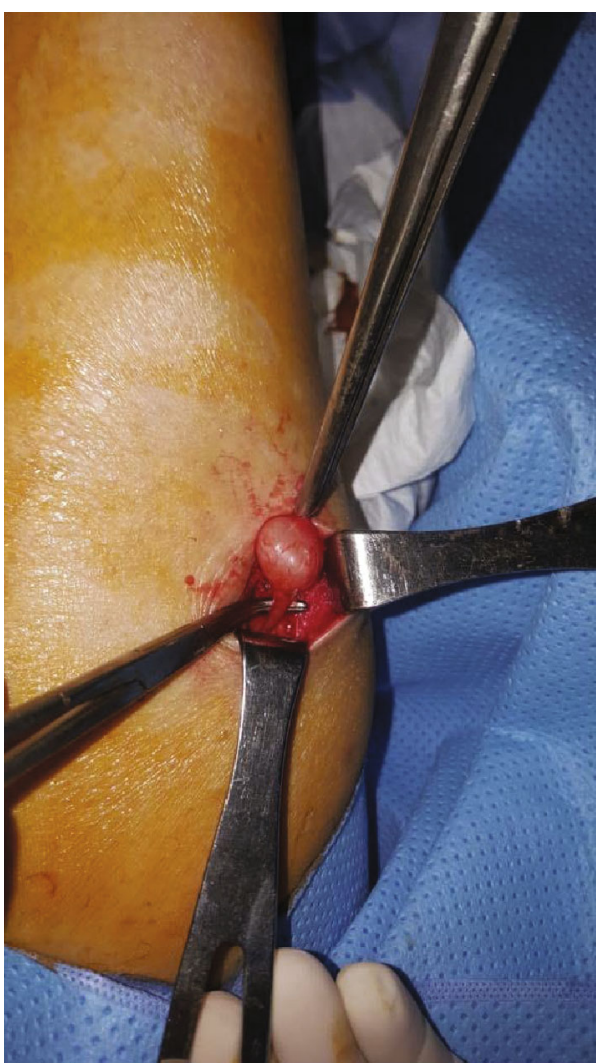

(a)

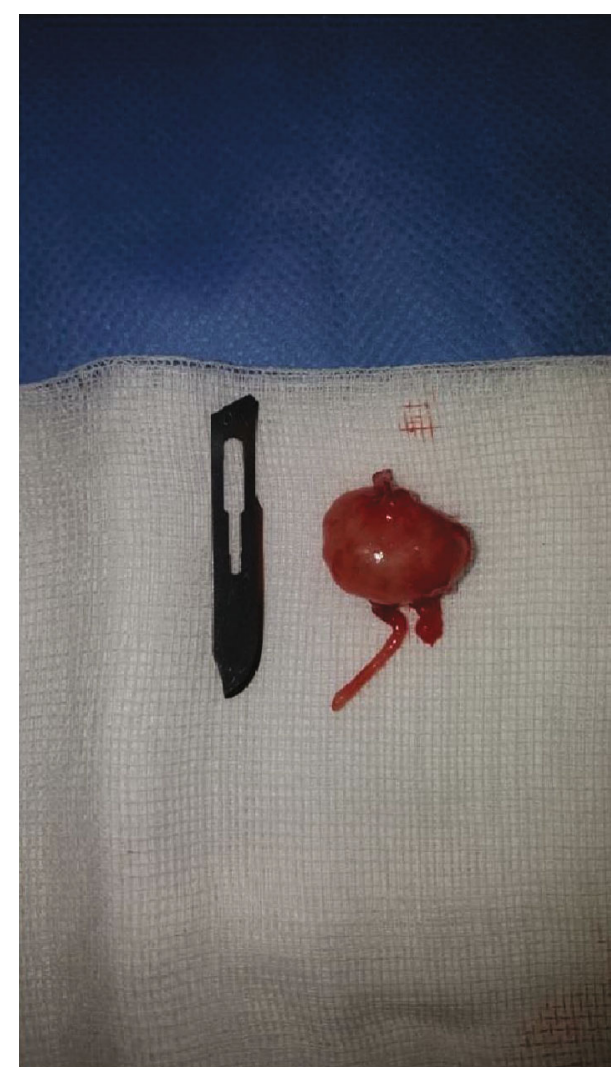

(b)

Figure 2: $(\mathrm{a}, \mathrm{b})$ Clinical aspect of the tumor mass.

At home, the patient did well, but he continued to experience intermittent pain in the same localization, which prevented him from carrying out his activities. One month later, he consulted our orthopedic department for further evaluations. On admission, he reported a localized moderate pain in the proximal medial side of his right leg, burning in type with no radiation, and it increased slightly with active and passive dorsiflexion of the foot. In this localization, the clinical examination found a firm mass measuring $2.5 \mathrm{~cm} / 2 \mathrm{~cm}$ mobile transversely and slightly longitudinally. The neurovascular examination was normal.

On investigation, he had a hemoglobin of $12 \mathrm{~g} / \mathrm{dl}$ and normal white blood cell counts, platelets, and D-dimer. Since the sonography of the leg was not conclusive, we performed, a few days later, a magnetic resonance imaging of the leg that was in favor of hemangioma or schwannoma (Figure 1), prompting the patient to undergo surgery. Thus, under spinal anesthesia along with tourniquet control, the entire tumor mass was shelled out carefully in one piece with no damage (Figure 2) and was sent for histopathological examination. At the first day postoperatively, clinical assessment of the patient found no pain and the neurovascular examination was normal reason for which we discharged him on oral analgesics waiting for the histopathological result. Ten days later, the result was concomitant with plexiform schwannoma with no sign of degeneration (Figures 3 and 4). 


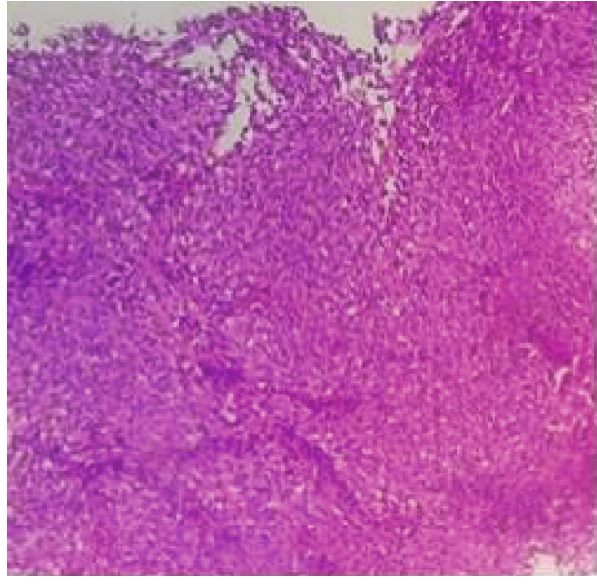

(a)

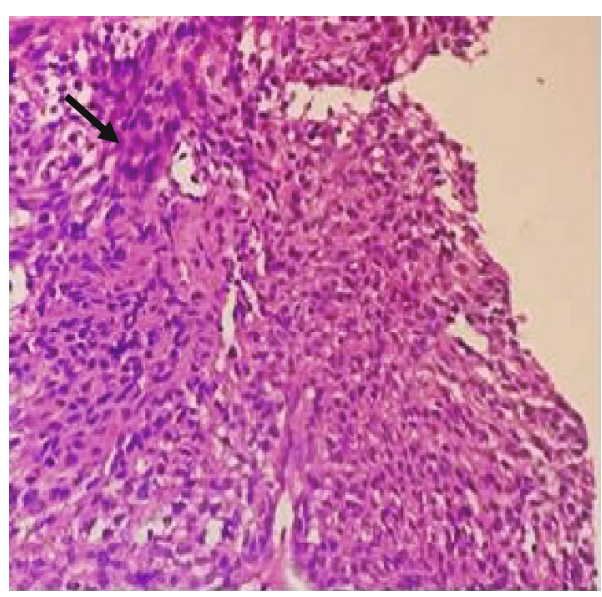

(b)

FIGURE 3: Histological section at low (a) and medium (b) magnification showing tumor proliferation. Note the Verocay bodies (black arrow) $(\mathrm{HE} \times 100$; HE $\times 200)$.

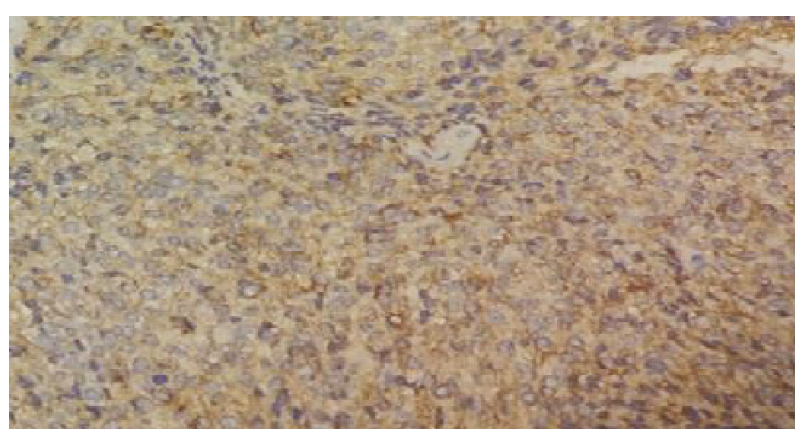

FIgURE 4: Immunohistochemical study showed a positive staining of the tumor cells by the anti-PS 100 .

At the last follow-up of sixteen months, he did not present any evidence of recurrent pain and he regained his previous level of sportive activities.

\section{Discussion}

For orthopedic surgeons taking care of athletes, chronic leg pain in athletes is a common complaint $[12,13]$. The main etiologies of this pain include medial tibial stress syndrome, chronic exertional compartment syndrome, tibial stress fracture, popliteal artery entrapment syndrome, Achilles tightness, deep vein thrombosis, complex regional pain, and nerve entrapment [14]. Our case presented an extremely rare case of atypical localization of plexiform schwannoma which caused chronic leg pain. Schwannoma is a benign encapsulated tumor that originates from Schwann cells in the peripheral nervous system [15]. Diagnosis is habitually incidental $[16,17]$, not as in our case. It typically is painless, slow-growing, isolated, firm, and round soft tissue mass [2]. The lesion is often mobile in a transverse direction but not longitudinally. It is frequently misdiagnosed as a ganglion and may have a similar consistency $[18,19]$. High-resolution ultrasonography, computed tomography, and magnetic resonance imaging had enhanced the preoperative diagnosis of nerve sheath tumors. However, the major limitation of highresolution ultrasonography is operator dependence. For computed tomography, it is irradiation [20,21]. For magnetic resonance imaging, it can be useful in delineating this lesion, but it may not be possible to distinguish neurilemoma from a neurofibroma or malignant peripheral nerve sheath tumor reason for which the pathological analysis of the operative specimen is necessary [22]. Most patients with a small solitary schwannoma are managed nonoperatively except if they manifest a progressive neurological deficit, pain, need for tissue diagnosis, or growth on serial imaging [23]. Surgically, schwannomas can be dissected carefully from the surrounding nerve while preserving the continuity of the nerve, in most cases, because those tumors repulse nerve fascicular groups without penetrating them [23]. Loss of function from smaller benign schwannomas is rare unless a prior biopsy had injured the involved nerve or an unsuccessful attempt at tumor removal had been performed. Its histology reveals spindle-shaped cells that are often palisading in a mixture of Antoni A and Antoni B patterns [24]. The Antoni A area is composed of spindle-shaped Schwann cells arranged in interlacing fascicles. There may be nuclear palisading. In between two compact rows of well-aligned nuclei, the cell processes form eosinophilic Verocay bodies. Mitotic figures may be present. The Antoni B area consists of a loose meshwork of gelatinous and microcystic tissue. Large, irregularly spaced, thick-walled blood vessels are noted in the Antoni B area. These may contain thrombus material in the lumina. Immunohistochemistry shows that S-100 stain was positive [25].

\section{Conclusion}

Although Schwannomas are uncommon, they should be considered as a possible cause of chronic leg pain. Its diagnosis is suggested by clinical and MRI examinations and is confirmed by histopathological analysis. 


\section{Consent}

Consent of the patient was obtained.

\section{Conflicts of Interest}

All authors declare that they have no conflict of interest.

\section{References}

[1] M. J. Kransdorf, "Benign soft-tissue tumors in a large referral population: distribution of specific diagnoses by age, sex, and location," American Journal of Roentgenology, vol. 164, no. 2, pp. 395-402, 1995.

[2] C. Yuk Kwan Tang, B. Fung, M. Fok, and J. Zhu, "Schwannoma in the upper limbs," BioMed Res Int., vol. 2013, pp. 14, 2013.

[3] J. C. Berg, B. W. Scheithauer, R. J. Spinner, C. M. Allen, and I. G. Koutlas, "Plexiform schwannoma: a clinicopathologic overview with emphasis on the head and neck region," Human Pathology, vol. 39, no. 5, pp. 633-640, 2008.

[4] G. Jerzy, R. Roman, and R. Jerzy, "Peripheral nerve tumours in own material," Folia Neuropathologica, vol. 42, no. 4, p. 5, 2004.

[5] J. Gosk, O. Gutkowska, J. Martynkiewicz, M. Bąk, and A. Hałon, "Schwannoma of the medial cutaneous nerve of the arm: a rare location with concomitant compression neuropathy of the ulnar nerve," Folia Neuropathologica, vol. 3, pp. 275-280, 2015.

[6] T. Judd, T. Jones, and L. Thornberry, "Schwannoma of the posterior tibial nerve: case study," Journal of the American Podiatric Medical Association, vol. 104, no. 5, pp. 539-543, 2014.

[7] M. Mahajan, R. Sharma, P. Sharma, and A. Gupta, "Schwannoma of superficial peroneal nerve presenting as leg pain," Journal of Case Reports, vol. 2, no. 2, pp. 79-82, 2012.

[8] S. A. Mohammed, M. M. Pressman, B. Schmidt, and N. Babu, "Case presentations and review of plexiform schwannoma in the foot," The Journal of Foot and Ankle Surgery, vol. 53, no. 2, pp. 179-185, 2014.

[9] R. Kapoor and B. R. Saxena, "Case series of peripheral nerve sheath tumours: schwannoma," Journal of Clinical and Diagnostic Research, 2018.

[10] C. Pino, H. Ghazle, S. Bhatt, and V. Dogra, "Schwannoma of the tibial nerve," Journal of Diagnostic Medical Sonography, vol. 26, no. 4, pp. 205-208, 2010.

[11] J. A. Lee and C. A. Boles, "Peripheral schwannoma lacking enhancement on MRI," American Journal of Roentgenology, vol. 182, no. 2, pp. 534-535, 2004.

[12] R. F. Pell IV, H. S. Khanuja, and R. G. Cooley, "Leg pain in the running athlete," Journal of the American Academy of Orthopaedic Surgeons, vol. 12, no. 6, pp. 396-404, 2004.

[13] P. H. Edwards Jr., M. L. Wright, and J. F. Hartman, "A practical approach for the differential diagnosis of chronic leg pain in the athlete," The American Journal of Sports Medicine, vol. 33, no. 8, pp. 1241-1249, 2005.

[14] M. T. Burrus, B. C. Werner, J. S. Starman et al., "Chronic leg pain in athletes," The American Journal of Sports Medicine, vol. 43, no. 6, pp. 1538-1547, 2015.
[15] R. E. Ferner and M. J. O’Doherty, "Neurofibroma and schwannoma," Current Opinion in Neurology, vol. 15, no. 6, pp. 679684,2002

[16] M. Incedayi, A. K. Sivrioglu, S. Ozyurek, and K. Kara, "Retroperitoneal ancient schwannoma: multidetector CT findings," BMJ Case Reports, vol. 2013, 2013.

[17] K. J. D’Silva, A. J. Dwivedi, and J. M. Barnwell, "Schwannoma of the psoas major muscle presenting with abdominal and back pain," Digestive Diseases and Sciences, vol. 48, no. 8, pp. 16191621,2003

[18] E. Rinaldi, "Neurilemomas and neurofibromas of the upper limb," The Journal of Hand Surgery, vol. 8, no. 5, pp. 590593, 1983.

[19] G. S. Phalen, "Neurilemmomas of the forearm and hand," Clinical Orthopaedics, vol. 1976, pp. 219-222, 1976.

[20] H.-W. Lin, J.-Y. Shieh, T.-G. Wang, W.-S. Chen, C.-L. Wang, and Y.-H. Wang, "Ultrasonographic features of schwannoma of the lower limb: two case reports," Medical Sciences, vol. 36, no. 3, pp. 169-175.

[21] G. Maleux, P. Brys, I. Samson, R. Sciot, and A. L. Baert, "Giant schwannoma of the lower leg," European Radiology, vol. 7, no. 7, pp. 1031-1034, 1997.

[22] M. A. Stull, R. P. Moser Jr., M. J. Kransdorf, G. P. Bogumill, and M. C. Nelson, "Magnetic resonance appearance of peripheral nerve sheath tumors," Skeletal Radiology, vol. 20, no. 1, pp. 9-14, 1991.

[23] A. Goyal, "Benign and malignant tumors of the peripheral nerve," in Youmans and Winn Neurological Surgery, Elsevier, 7 edition, 2017, Chapter: 258.

[24] F. Ballesteros, I. Vilaseca, J. L. Blanch, A. Gaspa, and M. Bernal-Sprekelsen, "Base of tongue neurilemmoma: excision by transoral laser microsurgery," Acta Oto-Laryngologica, vol. 127, no. 9, pp. 1005-1007, 2007.

[25] P. S. Padasali, V. S. Shankaregowda, and S. D. Kshirsagar, "Median nerve schwannoma: a case and review of literature," Asian Journal of Neurosurgery, vol. 10, no. 3, pp. 212-215, 2015. 


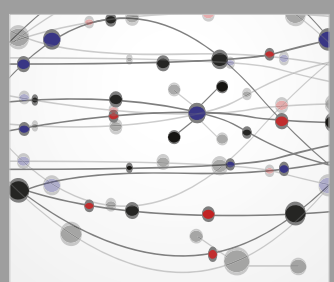

The Scientific World Journal
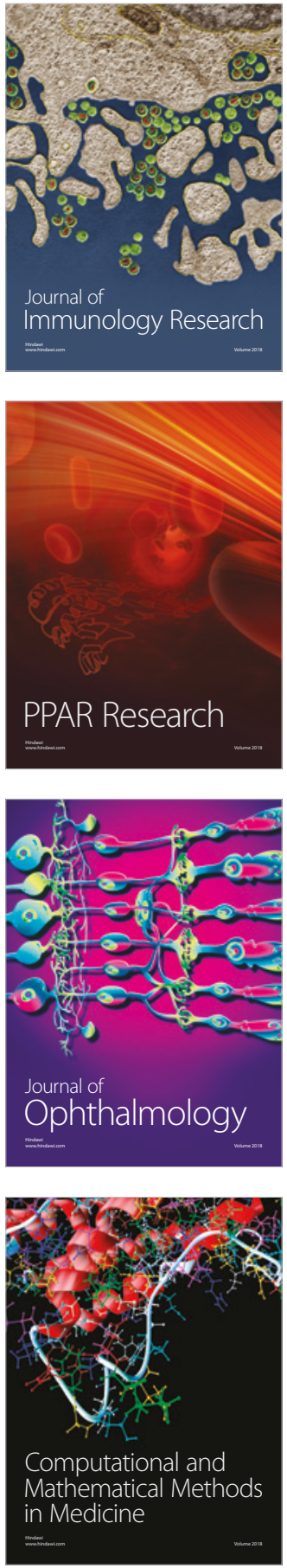

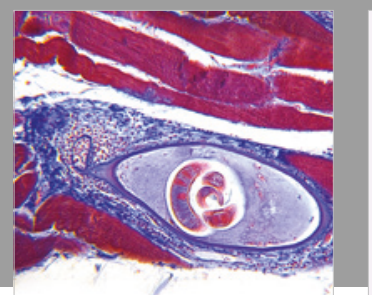

Gastroenterology Research and Practice

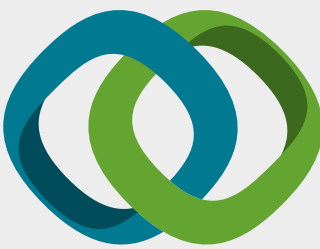

\section{Hindawi}

Submit your manuscripts at

www.hindawi.com
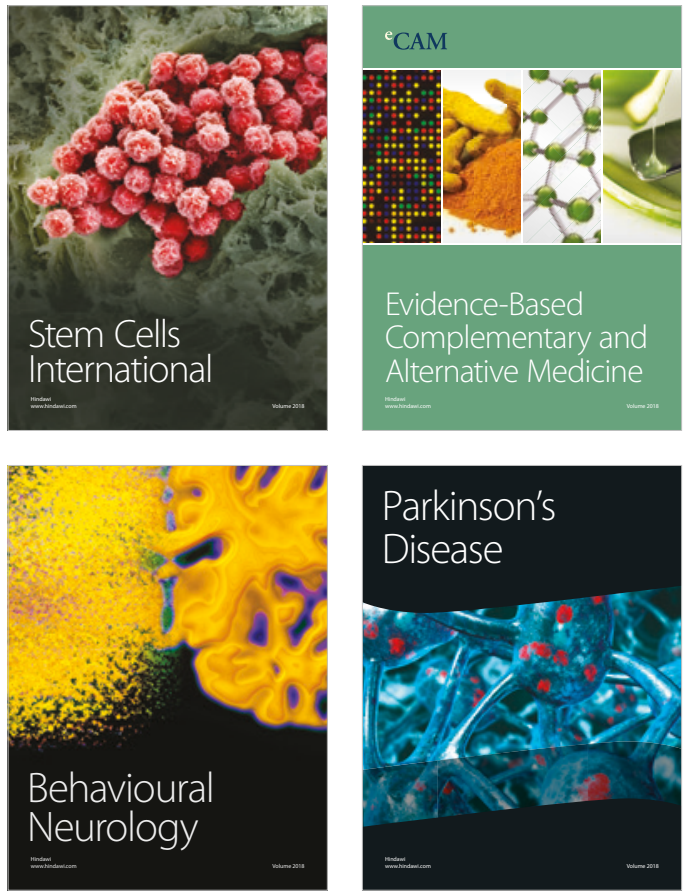

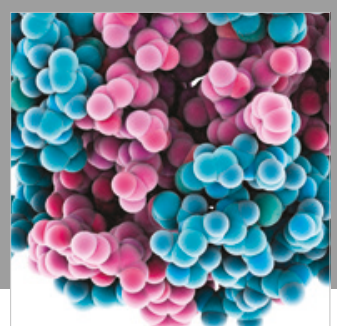

ournal of

Diabetes Research

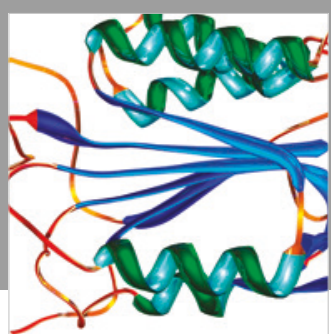

Disease Markers
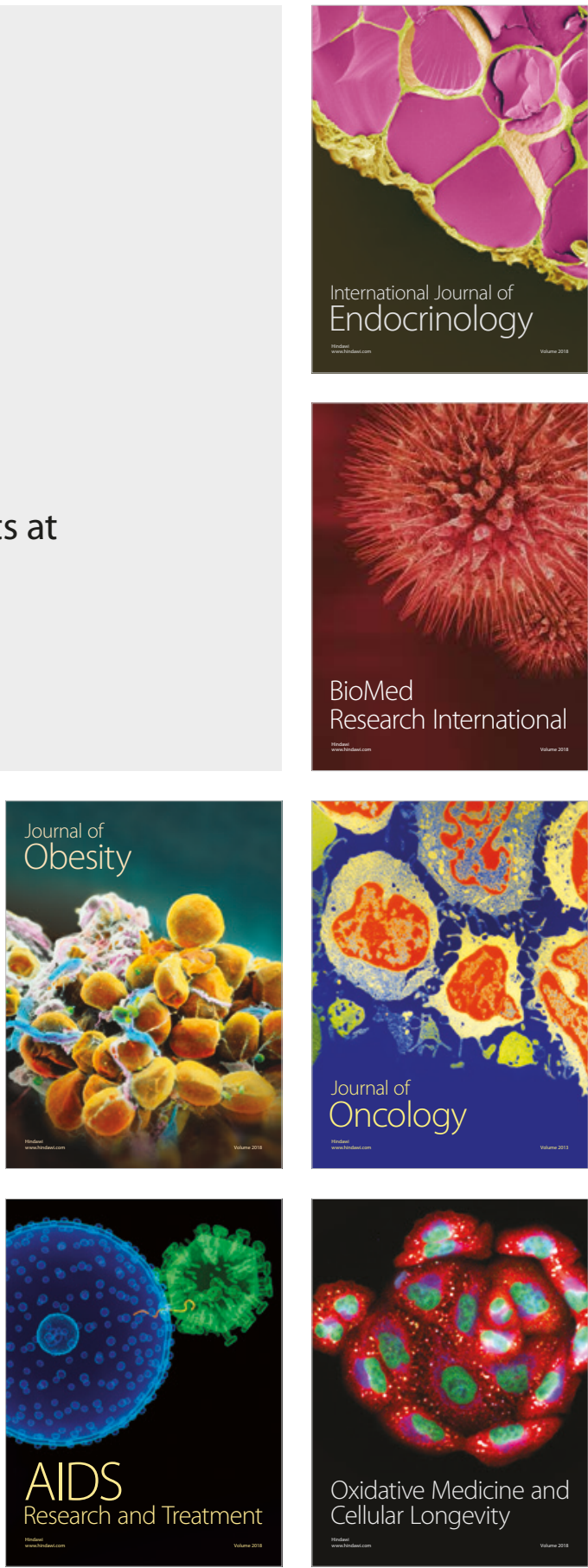